\title{
ASUHAN KEBIDANAN KOMPREHENSIF PADA NY "S" DENGAN INFEKSI POST SC HARI KE-16 DI RSUD Dr. SOEGIRI LAMONGAN TAHUN 2015
}

\author{
Nur Hasanah* \\ Puji Wardayanti**
}

*Dosen Program Studi Diploma III Kebidanan Universitas Islam Lamongan **Mahasiswa Program Studi Diploma III Kebidanan Universitas Islam Lamongan

\section{RINGKASAN}

Infeksi luka Post Sectio Caesarea merupakan kondisi dimana tubuh mengalami perubahan patologis yang disebabkan oleh luka jahitan sayatan persalinan abdominal yang menyebabkan cedera seluler dan beberapa multiplikasi mikroorganisme sehingga menyebabkan sakit. Di RSUD Dr. Soegiri Lamongan pada Bulan Januari-Juni Tahun 2015 terdapat 5,7\% infeksi luka Post Sectio Caesarea. Metode yang dipakai dalam penyusunan laporan tugas akhir ini deskriptif observasi yang dilaksanakan dengan pendekatan kohort mulai dari kehamilan sampai kontrasepsi diperoleh melalui wawancara, pengkajian data primer, sekunder, pemeriksaan fisik, penunjang dan dilakukan pendokumentasian standar asuhan kebidanan SOAP.

Berdasarkan hasil studi kasus diperoleh data bahwa nutrisi yang buruk selalu menjadi faktor penyebab dari infeksi luka Post Sectio Caesarea dibuktikan oleh teori bahwa faktor penyebab infeksi luka Post Sectio Caesarea antara lain sistem imunologik, respon ibu terhadap benang jahit, status nutrisi yang buruk, penyakit pada host, obesitas, lamanya waktu tunggu pre operasi di rumah sakit, umur, obat-obat yang digunakan, personal hygiene. Diharapkan dengan pelaksanaan asuhan kebidanan komprehensif dapat meningkatkan peran fungsi bidan dengan memberikan HE agar tidak melakukan pantangan dalam hal makan dan minum pada ibu nifas dengan infeksi luka Post Sectio Caesarea.

\section{Kata kunci : Infeksi, Post Sectio Caesarea, Nifas}

\section{PENDAHULUAN}

Infeksi luka Post Sectio Caesarea merupakan kondisi dimana tubuh mengalami perubahan patologis yang disebabkan oleh luka jahitan sayatan persalinan abdominal yang menyebabkan cedera seluler dan beberapa multiplikasi mikroorganisme sehingga menyebabkan sakit.

Infeksi potensial terjadi tergantung pada beberapa faktor, diantaranya yang terpenting adalah jumlah bakteri yang memasuki luka, tipe dan virulensi bakteri, serta pertahanan tubuh host, dan faktor eksternal lainnya. Juga beberapa faktor resiko yang dapat mempengaruhi terjadinya infeksi luka Post Sectio Caesarea diantaranya yakni dikarenakan sistem imunologik, respon ibu terhadap benang jahit, status nutrisi yang buruk, penyakit pada host, kegemukan, lamanya waktu tunggu pre operasi di rumah sakit, umur, obat-obat yang digunakan, personal hygiene dan lainnya yang semuanya 
menghambat proses penyembuhan luka bekas Sectio Caesarea serta tidak menutup kemungkinan faktor lingkungan juga sangat mempengaruhi terjadinya infeksi luka Post Sectio Caesarea. Luka dinyatakan terkena infeksi, menjadi abses atau selulitis bila terdapat tanda-tanda inflamasi yaitu tumor (massa, edema), kalor (kenaikan suhu), rubor (warna kemerahan/eritema), dolor (rasa nyeri), dan functiolaesa. Dampak apabila ibu nifas mengalami infeksi luka Post Sectio Caesarea dan tidak segera ditangani akan mengakibatkan terjadinya kerusakan pada jaringan epidermis maupun dermis, gangguan pada sistem persyarafan, dan kerusakan jaringan seluler.

Data yang didapat dari RSUD Dr. Soegiri Lamongan pada Bulan Januari-Desember Tahun 2013 terdapat $410 \mathrm{ibu}$ nifas dengan ibu nifas post SC sebanyak 405 orang dan dari 405 orang ibu nifas post SC tersebut yang mengalami infeksi luka post SC sebanyak 1 orang $(0,2 \%)$. Data RSUD Dr. Soegiri Lamongan pada Bulan Januari-Desember Tahun 2014 terdapat $438 \mathrm{ibu}$ nifas dengan ibu nifas post SC sebanyak 428 orang dan dari 428 orang ibu nifas post SC tersebut yang mengalami infeksi luka SC sebanyak 2 orang $(0,5 \%)$. Data RSUD Dr. Soegiri Lamongan pada Bulan Januari-Juni Tahun 2015 terdapat $220 \mathrm{ibu}$ nifas, ibu nifas fisiologis 115 orang $(52,2 \%)$, ibu nifas post SC sebanyak 105 orang $(47,7 \%)$ dari 105 orang yang mengalami infeksi 6 orang $(5,7 \%)$ yang tidak mengalami infeksi 99 orang $(94,3 \%)$. Yang mengalami infeksi akibat kehamilan dengan DM sebanyak 2 orang $(33,3 \%)$ sedangkan yang mengalami infeksi akibat kehamilan dengan anemia sebanyak
2 orang $(33,3 \%)$ dan yang mengalami infeksi akibat persalinan dengan KPD sebanyak 2 orang $(33,3 \%)$.

Usaha yang dilakukan adalah melakukan deteksi dini adanya penyulit maupun komplikasi pada ibu hamil dan nifas, dengan perawatan yang komprehensif dan tepat sejak masa kehamilan dengan melakukan penyuluhan mengenai pola kebiasaan sehari-hari, tanda bahaya kehamilan dan nifas, deteksi dini adanya komplikasi atau penyulit pada masa kehamilan dan nifas serta perawatan diri. Peneliti mengharapkan tidak ada lagi Post Sectio Caesarea dengan infeksi.

\section{Tujuan Penelitian}

Tujuan penelitian ini adalah mendapat gambaran nyata tentang teori dan praktek lapangan untuk mengembangkan pola pikir dalam melaksanakan asuhan kebidanan dengan menggunakan manajemen kebidanan (SOAP) pada Asuhan Kebidanan Komprehensif Pada $\mathrm{Ny}$ "S" Dengan Infeksi Post SC Hari Ke16 Di RSUD Dr. Soegiri Lamongan Tahun 2015.

\section{PEMBAHASAN}

\section{Pengkajian Data Subyektif}

Pada data subyektif terdapat persamaan antara tinjauan kasus dengan tinjauan pustaka. Pada tinjauan kasus untuk data sosial budaya ibu melakukan pantangan dalam hal makan dan minum. Pada tinjauan pustaka untuk data sosial budaya ibu melakukan pantangan dalam hal makan dan minum.

Melakukan pantangan dalam hal makan dan minum akan mempengaruhi nutrisi ibu, nutrisi menjadi kurang sehingga ibu mendapat status nutrisi yang buruk. 
Dibuktikan dengan teori bahwa faktor penyebab infeksi luka Post Sectio Caesarea antara lain sistem imunologik, respon ibu terhadap benang jahit, status nutrisi yang buruk, penyakit pada host, obesitas, lamanya waktu tunggu pre operasi di rumah sakit, umur, obat-obat yang digunakan, personal hygiene.

\section{Pengkajian Data Objektif}

Pada data obyektif terdapat persamaan antara tinjauan kasus dengan tinjauan pustaka. Pada tinjauan kasus, didapatkan pemeriksaan fisik abdomen, luka jahitan bekas operasi yang masih basah dan belum sembuh, keadaan luka sedikit terbuka, serta terdapat warna kemerahan, bengkak dan mengeluarkan cairan berwarna kuning yang berbau pada luka Post Sectio Caesarea. Pada tinjauan pustaka untuk pemeriksaan fisik abdomen, luka jahitan bekas operasi yang masih basah pada bagian atas, luka yang terbuka $5 \mathrm{~cm}$, dan menggunakan jahitan jelujur, serta terdapat warna kemerahan, bengkak dan mengeluarkan cairan berwarna kuning yang berbau pada luka Post Sectio Caesarea.

Warna kemerahan pada pemeriksaan fisik abdomen menunjukkan tanda gejala adanya infeksi pada luka Post Sectio Caesarea. Dibuktikan dengan teori bahwa pada pemeriksaan fisik abdomen, jahitan dikulit perut terlihat merah dan meradang.

\section{Analisa Data}

Masalah potensial terdapat persamaan antara tinjauan kasus dengan tinjauan pustaka. Pada tinjauan kasus masalah potensial yang terjadi sepsis dan syok. Pada tinjauan pustaka masalah potensial yang terjadi sepsis dan syok.

Sepsis dan syok ini menjadi masalah potensial pada Ny "S" sehingga diperlukan kebutuhan seperti perawatan luka, perbaikan nutrisi, mobilisasi dini, pemberian antibiotik, antipiretik dan analgesik. Dibuktikan dengan teori bahwa masalah potensial yang terjadi sepsis dan syok dapat di cegah dengan memberikan kebutuhan seperti perawatan luka, perbaikan nutrisi, mobilisasi dini, pemberian antibiotik, antipiretik dan analgesik.

\section{Penatalaksanaan}

Merupakan pelaksanaan asuhan yang menyeluruh, pada tinjauan kasus dan tinjauan pustaka ditemukan persamaan. Pada tinjauan kasus melakukan dan mengajarkan cara perawatan luka. Pada tinjauan pustaka melakukan dan mengajarkan cara perawatan luka.

Dengan melakukan dan mengajarkan cara perawatan luka, luka Post Sectio Caesarea akan sembuh dan kering setelah 2 minggu dilakukan asuhan kebidanan nifas dengan infeksi Post Sectio Caesarea. Dibuktikan dengan teori bahwa luka Post Sectio Caesarea akan sembuh dan kering selama 2 minggu.

\section{KESIMPULAN Simpulan}

Pada Data Subyektif terdapat persamaan antara tinjauan kasus dengan tinjauan pustaka untuk data sosial budaya pada nifas dengan infeksi. Data Obyektif terdapat persamaan antara tinjauan kasus dengan tinjauan pustaka untuk pemeriksaan fisik abdoment pada nifas dengan infeksi. Analisa Data terdapat persamaan antara tinjauan kasus dengan tinjauan pustaka untuk 
masalah potensial pada nifas dengan infeksi. Penatalaksanaan terdapat persamaan antara tinjauan kasus dengan tinjauan pustaka untuk melakukan dan mengajarkan cara perawatan luka pada nifas dengan infeksi.

\section{Saran}

Dapat dijadikan sebagai bahan masukan atau tambahan untuk perkembangan dan penyempurnaan yang sudah ada pada nifas dengan infeksi luka Post Sectio Caesarea. Diharapkan dapat menyediakan lebih banyak literatur dengan tahun terbaru dalam menyusun Laporan Tugas Akhir khususnya pada nifas dengan infeksi luka Post Sectio Caesarea. Diharapkan dapat meningkatkan kualitas pelayanan bagi petugas dan klien sehingga tercapai asuhan kebidanan yang lebih komprehensif.

Mendapatkan informasi mengenai nifas dengan infeksi luka Post Sectio Caesarea sehingga masyarakat mengerti dan memahami serta dapat mencegah terjadinya infeksi luka Post Sectio Caaesarea.

\section{DAFTAR PUSTAKA}

Dr. Suparyanto, M.Kes. 2011. Infeksi Luka Operasi. http://dr-

suparyanto.blogspot.com/20 11/03/konsep-infeksi-lukaoperasi.html. Diaksses pada hari Kamis tanggal 07 Mei 2015.

Fakultas Kedokteran. 2009. Referat Infeksi Luka Operasi. http://referensikedokteran.bl ogspot.com/2010/08/referatinfeksi-luka-operasi.html. Diakses pada hari Kamis tanggal 07 Mei 2015.
Mansjoer, Arif. 2007. Kapita Selekta Kedokteran Jilid I Edisi ketiga. Jakarta : Media Aesculapius Fakultas Kedokteran Universitas Indonesia.

Perry \& Potter. 2007. Buku Ajar Fundamental Keperawatan Volume 1. Jakarta : EGC.

Prawirorahardjo, Sarwono. 2007. Ilmu Kebidanan. Jakarta: Bina Pustaka Sarwono Prawirorahardjo.

Saifudin, Abdul Bari. 2007. Panduan Pencegahan Infeksi untuk Fasilitas Pelayanan Kesehatan dengan Sumber Daya Terbatas. Jakarta : YBP-SP. 